\title{
Analysis of Obstetrical Lethality in the Department of Gynecology and Obstetrics of the University Teaching Hospital Yalgado OUEDRAOGO (UTH-YO)
}

\author{
Ouattara Adama ${ }^{1,}$, , Kiemtoré Sibraogo ${ }^{1}$, Sawadogo Yobi Alexis ${ }^{1}$, Ouédraogo Issa ${ }^{2}$, Barry Fatimata ${ }^{1}$, \\ Traoré/Millogo Francoise Danielle ${ }^{1}$, Ouédraogo Charlemagne Marie Rayangwende ${ }^{1}$, \\ Ouédraogo Ali ${ }^{1}$, Thieba/Bonané Blandine ${ }^{1}$ \\ ${ }^{1}$ Department of Gynecology-Obstetrics of the UFR/SDS of the Joseph KI ZERBO University, Ouagadougou, Burkina Faso \\ ${ }^{2}$ Ouahigouya Regional University Hospital Centre, Ouahigouya, Burkina Faso
}

\author{
Email address: \\ ouattzangaadama@yahoo.fr (O. Adama) \\ ${ }^{*}$ Corresponding author
}

\section{To cite this article:}

Ouattara Adama, Kiemtoré Sibraogo, Sawadogo Yobi Alexis, Ouédraogo Issa, Barry Fatimata, Traoré/Millogo Francoise Danielle, Ouédraogo Charlemagne Marie Rayangwende, Ouédraogo Ali, Thieba/Bonané Blandine. Analysis of Obstetrical Lethality in the Department of Gynecology and Obstetrics of the University Teaching Hospital Yalgado OUEDRAOGO (UTH-YO). Journal of Gynecology and Obstetrics. Vol. 9, No. 1, 2021, pp. 14-20. doi: 10.11648/j.jgo.20210901.14

Received: January 31, 2021; Accepted: February 8, 2021; Published: February 27, 2021

\begin{abstract}
Objectives: Analyze the determinants of obstetric lethality in the Department of Obstetrical Gynecology at the University Teaching Hospital Yalgado OUEDRAOGO (UTH-YO) of Ouagadougou from 2015 to 2018. Methodology: We conducted an analytical, descriptive cross-sectional study on maternal deaths in the UTH-YO. The data were collected retrospectively. All patients meeting the World Health Organization (WHO) definition of maternal death and patients who died as a result of direct obstetric complications in the Department of Gynaecology and Obstetrics at the University Teaching Hospital Yalgado OUEDRAOGO (UTH-YO) of Ouagadougou from January 1, 2015 to December 31, 2018 were included. Results: We recorded 484 maternal deaths and 22947 births, for a maternal mortality ratio of 2109 deaths per 100,000 live births (NV). Patients who died as a result of direct obstetric complications accounted for 412 out of 10,564 cases, representing an obstetric lethality rate of $3.9 \%$. These were patients with an average age of 27.6 years, without income generating activities (93.6\%), nulliparous and pauciparous patients respectively (26\%) and (31\%). Most of them came from health facilities in the city of Ouagadougou (50\%). The 4 main causes of death were haemorrhages (29.7\%), hypertensive disorders (20.8\%), abortion complications (16.8\%) and infections (14\%) respectively. The most lethal causes were thromboembolic pathology $(27.27 \%)$, infections (13\%), abortion complications (7.6\%), bleeding (5.4\%) and hypertensive disorders (4.2\%). The notion of the 3 delays, the insufficient technical platform, the lack of financial resources and the lack of staff qualification were the contributing factors to the causes of death. Conclusion: From our study, it appears, as elsewhere, that most maternal deaths are preventable, hence the need for coordinated action to take effective action against maternal mortality.
\end{abstract}

Keywords: Direct Obstetric Complication, Lethality, UTH-YO, Ouagadougou

\section{Introduction}

In Burkina Faso, the maternal mortality ratio was 307 per $100,000 \mathrm{NV}$ in 2010 [13]. It should be noted that the main causes of maternal deaths in Burkina Faso are haemorrhages, infections, complications of unsafe abortions, hypertensive disorders and dystocias $[13,14,21]$. Indeed, direct obstetric causes account for more than two thirds of deaths. According to the national committee for monitoring the implementation of maternal and neonatal mortality reduction strategy programmes: in 2012 there were 702 cases of maternal death compared to 532 cases of maternal death in 2013 [14, 21]. This decrease in mortality is explained by strategies such as the creation of medical centres with surgical antenna, training of health centre providers, state subsidies to emergency 
obstetric care centres, the availability of contraceptive products and control of the distribution channel for reproductive health products. Indeed, the points of service increased from $25 \%$ in 2012 to $75 \%$ in 2013 [14].

Despite these different strategies adopted, we can see that the figures are still very high. Thus, improving maternal health remains one of the development priorities adopted by the international community to reduce maternal mortality at $3 / 4$ between 1990 and 2015 [15].

The objective of our study was to analyze the different complications, especially direct obstetric complications and determine their impact on maternal mortality while identifying contributing factors to better guide policy makers and health authorities in strengthening the strategy for improving maternal and child health.

\section{Patients and Methods}

\subsection{Framework of the Study}

Our study took place in the obstetrical gynaecology department of the University Teaching Hospital Yalgado OUEDRAOGO (UTH-YO) of Ouagadougou. The UTH-YO is one of the reference centres in Burkina Faso and is located in the heart of the city of Ouagadougou. It contributes to the training of medical students, pharmacies and students at the National School of Public Health. It is divided into 10 departments, including the Gynaecology-Obstetrics Department, which receives gynaecological and obstetrical emergencies from the city of Ouagadougou and the surrounding provinces. It is divided into 3 departments: the Gynaecology Department, the Obstetrics Department and the Family Planning Department.

\subsection{Type and Period of Study}

This was a descriptive, analytical, cross-sectional study conducted over a four-year period (04) from 1 January 2015 to 31 December 2018. The data were collected retrospectively.

\subsection{Study Population}

Our study examined patients admitted for direct obstetric complications as well as those with the same types of complications after admission. In our study, patients who died as a result of direct obstetric complications in the Department of Gynaecology and Obstetrics at UTH-YO were included in the period from 1 January 2015 to 31 December 2018. Patients who met the inclusion criteria but whose medical records were unusable were not included in our study. With regard to the mode of termination of pregnancy, we have selected five modes of termination of pregnancy: the lower route, cesarean section, pregnancy not expelled before death, abortion, laparotomy.

\subsection{Data Collection}

The data collection medium was the collection sheet. Our data were collected from patient clinical records, admission records, birth records, operating room records and maternal death records during the study period. The variables taken into account were: marital status, age, occupation, marital status, mode of admission, origin, time of evacuation, reason for evacuation, distance travelled to UTH-YO, history, pregnancy follow-up, clinical signs, diagnoses selected, therapeutic modalities, causes, time of death and factors contributing to maternal deaths.

\subsection{Data Analysis}

The data were entered and analyzed on a computer using the statistical analysis software EPI info version 3.5.1 and EPI data. The graphs were created using the EXCEL spreadsheet Version 2013.

\subsection{Operational Definitions}

Lethality rate: Number of deaths related to a condition as a proportion of the total number of cases of that condition

Obstetric Lethality Rate: Number of maternal deaths related to direct obstetric causes as a proportion of the total number of cases of direct obstetric complications.

Late maternal death: is defined as the death of a woman from direct or indirect obstetric causes beyond 42 days, but less than one year after the termination of pregnancy.

\section{Results}

\subsection{Frequency}

\subsubsection{Number of Maternal Deaths by Direct Causes}

During the study period, 412 deaths related to direct obstetric complications were recorded for 10,564 admissions due to these complications, representing a frequency of $3.9 \%$. The distribution of maternal deaths and admissions by year has been presented in Table 1 .

Table 1. Annual distribution of maternal deaths and admissions due to direct obstetric complications.

\begin{tabular}{llll}
\hline Year & Maternal Deaths & Maternal deaths due to direct obstetric complications & Admissions due to direct obstetric complications \\
\hline 2012 & 98 & 69 & 2905 \\
2013 & 115 & 105 & 2818 \\
2014 & 121 & 110 & 2396 \\
2015 & 150 & 128 & 2445 \\
\hline
\end{tabular}

\subsubsection{Maternal Mortality Ratio}

During our study period, we recorded 484 maternal deaths and 22947 births, for a ratio of 2109 deaths per 100,000 live births. Figure 1 shows the evolution of the different maternal mortality ratios from 2012 to 2015 . 
RATIO OF MATERNAL MORTALITY

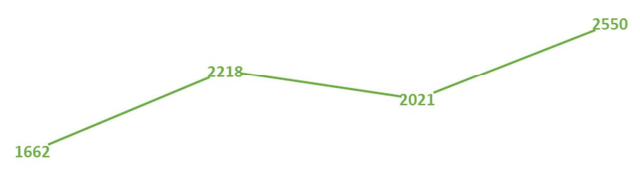

2015

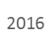

2017

2018

Figure 1. Evolution of maternal mortality ratio from 2015 to 2018.

\subsubsection{Birth Rate of Lethality}

From 1 January 2012 to 31 December 2015, we recorded a total of 412 maternal deaths out of 10,564 patients admitted for direct obstetric complications, for an obstetric lethality rate of $3.9 \%$.

Table 2 presents the annual obstetric fatality rate from 2012 to 2015 . There is an increase in the case-fatality rate from 2012 to 2015 .

Table 2. Annual presentation of the obstetric lethality rate from 2015 to 2018

\begin{tabular}{llll}
\hline Year & $\begin{array}{l}\text { Death due to direct } \\
\text { obstetric complications }\end{array}$ & $\begin{array}{l}\text { Number of } \\
\text { cases }\end{array}$ & $\begin{array}{l}\text { Lethality } \\
\text { rate (\%) }\end{array}$ \\
\hline 2012 & 69 & 2905 & 2.3 \\
2013 & 105 & 2818 & 3.7 \\
2014 & 110 & 2396 & 4.6 \\
2015 & 128 & 2445 & 5.2 \\
\hline
\end{tabular}

The distribution of the specific lethality of the different direct obstetric complications is presented in Table 3. Only the lethality of the dystocia was less than $1 \%$.

Table 3. Lethality rate for each of the direct obstetric complications.

\begin{tabular}{llll}
\hline Direct obstetric complications & $\begin{array}{l}\text { Number } \\
\text { of cases }\end{array}$ & $\begin{array}{l}\text { Number } \\
\text { of deaths }\end{array}$ & $\begin{array}{l}\text { Lethality } \\
\text { rate (\%) }\end{array}$ \\
\hline Hemorrhages & 2555 & 138 & 5.4 \\
Abortion complications & 1297 & 99 & 7.6 \\
Hypertensive disorders & 2034 & 87 & 4.2 \\
Infections & 544 & 71 & 13 \\
Thromboembolic disorders & 11 & 3 & 27.27 \\
dystocias & 4123 & 14 & 0.3 \\
\hline
\end{tabular}

\subsection{Sociodemographic Characteristics}

\subsubsection{Age}

The extreme ages were 12 and 47 years with an average age of $27.6 \pm 6$ years. The $20-24$ age group with 66 cases accounted for $21.4 \%$ of cases. More than half of the deceased women (190) were under 30 years of age or $61.9 \%$.

\subsubsection{Parity of Deceased Women}

The highest parity observed was 7 , with an average parity of $2.1 \pm 2$.

\subsubsection{Socio-professional Status}

The socio-professional status of women was clarified in 234 cases. There were 219 women without incomegenerating activities (housewives, pupils and students), or $93.6 \%$.

\subsubsection{Marital Status}

Single deceased patients accounted for $26.7 \%$, those leading a married life (concubines or married) accounted for $73.3 \%$.

\subsubsection{Pregnancy History}

\section{1) Special history}

Nineteen (19) deceased patients had positive HIV status, 21 or $26 \%$ were major sickle cell disease, 7 or $8.7 \%$ were known to have high blood pressure, 3 or $4 \%$ were known to have diabetes and 2 or 3.1 had known and monitored heart disease.

2) Number of prenatal consultations (ANC)

The number of ANCs performed ranged from 0 to 5 with an average of 1.28. Patients with at least 3 ANC accounted for $25.2 \%$.

\subsection{Clinical Aspects}

\subsubsection{Distance Travelled to Reach UTH-YO}

The distance travelled to reach UTH-YO was specified in 249 cases. Deceased patients from a community more than $100 \mathrm{~km}$ away accounted for $23.5 \%$. The average distance travelled was $62.2 \mathrm{~km}$. The extremes ranged from $0 \mathrm{~km}$ to $225 \mathrm{~km}$.

\subsubsection{Diagnostics Selected}

The main diagnoses selected have been grouped together in Table 4. Bleeding, including delivery period bleeding, postpartum bleeding, placental abruptio, uterine rupture and placenta previa, accounted for $29.7 \%$ of the diagnoses selected.

Table 4. Distribution of deceased patients by main diagnoses $(n=346)$.

\begin{tabular}{lll}
\hline Main diagnoses & Number & Percentage \\
\hline Pre-eclampsia/Eclampsia & 72 & 20.8 \\
Hemorrhage from the period of delivery & 65 & 18.7 \\
Abortion complications & 58 & 16.8 \\
Severe anemia & 53 & 15.3 \\
Infections & 48 & 14 \\
Postpartum hemorrhage & 38 & 11 \\
Others & 12 & 3.4 \\
Total & 346 & 100 \\
\hline
\end{tabular}

\subsubsection{Period of Death}

Table 5 shows the distribution of deceased women by period of death. Women who died in the postpartum period accounted for $43 \%$.

Table 5. Distribution of deceased women by period of death $(n=231)$.

\begin{tabular}{lll}
\hline Period of occurrence & Number & Percentage (\%) \\
\hline $1^{\text {st }}$ trimester & 17 & 7.4 \\
$2^{\text {nd }}$ trimester & 42 & 18.3 \\
$3^{\text {rd }}$ trimester & 72 & 31.3 \\
Post-partum & 99 & 43 \\
Total & 230 & 100 \\
\hline
\end{tabular}




\subsection{Therapeutic Aspects}

\subsubsection{Time to Take Charge of an Intervention}

Fifteen of the patients died (15) after being admitted to the emergency room for surgery. Extreme delays in obstetric care ranged from 20 to 180 minutes with an average of 108 minutes. Table 6 shows the distribution of deceased women by time of surgical management. Nine $(60 \%)$ of the deceased patients received surgical management after more than an hour of waiting.

Table 6. Distribution of deceased women by time of surgical management $(n=15)$.

\begin{tabular}{lll}
\hline Time Limit & Number & Percentage \\
\hline $0-10 \mathrm{mn}$ & 0 & 0 \\
$11-20 \mathrm{mn}$ & 2 & 13.3 \\
$21-30 \mathrm{mn}$ & 1 & 6,7 \\
$31-60 \mathrm{mn}$ & 3 & 20 \\
More than $60 \mathrm{mn}$ & 9 & 60 \\
Total & 15 & 100 \\
\hline
\end{tabular}

\subsubsection{Mode of Pregnancy Termination}

Table 7 provides a breakdown of deceased patients by mode of pregnancy termination. The mode of termination of pregnancy could not be specified in 16 patients.

Table 7. Distribution by mode of termination of pregnancies of deceased patients $(n=396)$.

\begin{tabular}{lll}
\hline Termination mode & Number & Percentage \\
\hline Low track & 212 & 53.6 \\
Pregnancy not expelled & 80 & 20.2 \\
Caesarean section & 12 & 3 \\
Abortion & 89 & 22.4 \\
Laparotomy (Uterine rupture, ectpic pregnancy ) & 3 & 0.8 \\
Total & 396 & 100 \\
\hline
\end{tabular}

Table 8. Distribution of maternal deaths by direct obstetric causes $(n=412)$.

\begin{tabular}{lll}
\hline Direct obstetrical causes & Number & Percentage (\%) \\
\hline bleeding & 138 & 33.5 \\
1. Hemorrhage from the period of delivery & 61 & 14.8 \\
2. Postpartum hemorrhage & 38 & 9.2 \\
3. Uterine rupture & 20 & 4.8 \\
4. Placental abruptio & 7 & 1.7 \\
5. Hemorrhagic shock & 6 & 1.6 \\
6. Placenta previa & 5 & 1.2 \\
7. Coagulation disorder & 1 & 0,2 \\
Abortion complications & 99 & 24 \\
Hypertensive disorders & 87 & 21.1 \\
1. Eclampsia & 83 & 20.1 \\
2. Pre-eclampsia & 3 & 0.8 \\
3. HELLP syndrome & 1 & 0.2 \\
Infections & 71 & 17.2 \\
1. Septic shock & 28 & 6.8 \\
2. Septicaemia & 26 & 6.3 \\
3. Endometritis & 11 & 2.7 \\
4. Pelviperitonitis & 6 & 1.4 \\
Dysocias & 14 & 3.4 \\
Thromboembolic disorders & 3 & 0.8 \\
Total & 412 & 100 \\
\hline
\end{tabular}

\subsection{Causes of Death}

1) Direct obstetrical causes
Direct obstetric causes accounted for $85.1 \%$ of maternal deaths and indirect causes for $14.9 \%$.

Table 8 shows the distribution of women who died by direct obstetrical causes. Deaths following abortion complications represent $24 \%$ after haemorrhages which represented $33.5 \%$.

2) Indirect obstetrical causes

Table 9 shows the distribution of women who died by indirect obstetric causes.

Table 9. Distribution of maternal deaths by indirect obstetric causes $(n=72)$.

\begin{tabular}{lll}
\hline Indirect obstetrical causes & Number & Percentage (\%) \\
\hline Chronic anemia & 33 & 45.8 \\
Malaria & 14 & 19.4 \\
Sickle cell disease & 5 & 7 \\
Hepatitis H & 4 & 5.6 \\
Meningitis & 3 & 4.1 \\
Cardiopathy & 3 & 4.1 \\
HIV/AIDS & 2 & 2.8 \\
Renal insufficiency & 1 & 1.4 \\
Others & 7 & 9.8 \\
Total & 72 & 100 \\
\hline
\end{tabular}

Other causes were: metabolic disorders, acute lung disease, acute intestinal obstruction, bleeding from perforated peptic ulcers and traffic accidents. The other causes are not due to pregnancy

3) Factors contributing to maternal deaths before admission Table 10 summarizes the factors contributing to maternal deaths before admission. The inadequacy of the technical platform was represented by the non-functional operating room, the lack of reagents in the laboratory, the closed blood bank and the lack or unavailability of specialists.

Table 10. Summary of factors contributing to maternal deaths before admission.

\begin{tabular}{lll}
\hline Contributing factors & Number & Percentage (\%) \\
\hline Delay in evacuation & 119 & 32.7 \\
Delay in consultation & 112 & 30.8 \\
Lack of financial resources & 72 & 19.8 \\
Insufficiency of the technical platform & 61 & 16.7 \\
\hline
\end{tabular}

4) Factors contributing to maternal deaths after admission

Table 11 summarizes the factors contributing to maternal deaths after admission.

Table 11. Summary of factors contributing to maternal deaths after admission.

\begin{tabular}{lll}
\hline Contributing factors & Number & Percentage (\%) \\
\hline Delay in taking charge & 97 & 31.4 \\
Lack of transfusion products & 84 & 27.2 \\
Lack of financial resources & 72 & 23.3 \\
Late diagnosis & 56 & 18.1 \\
\hline
\end{tabular}

\subsection{Length of Hospital Stay}

The duration varies from a few minutes to 45 days. Table 12 summarizes the distribution of deceased patients by length of hospital stay. 
Table 12. Distribution of deceased patients by length of hospitalization.

\begin{tabular}{lll}
\hline Length of hospital stay & Number & Percentage \\
\hline$\leq 24$ hours & 204 & 50.4 \\
25-72 hours & 77 & 19 \\
$96-144$ hours & 68 & 16.8 \\
$\geq 168$ hours & 56 & 13.8 \\
Total & 405 & 100 \\
\hline
\end{tabular}

\section{Discussion}

\subsection{Frequency}

In our study, the number of maternal deaths gradually increased over the years 2012 to 2015 , with in 2012 (98 deaths), 2013 (115 deaths), 2014 (121) and 2015 (150 deaths). Akpadza and al. [2] in Lomé on a study conducted from 1987 to 2007 noted a gradual increase in the number of deaths over the years. The maternal mortality ratio of 2109 deaths per 100,000 live births is high compared to some series:

1) 1933 per 100,000 live births in the Akpadza and al. [2] in Lomé.

2) 1245 per 100,000 live births in the Andria Mady and al. $3]$ in Antananarivo.

3) 604 per 100,000 live births in Takpara and al. [20] in Cotonou.

4) 30.4 per 100,000 live births in the Hamouda and al. [9] in Tunis.

The maternity ward at UTH-YO remains the last level of the health pyramid. The malfunction of some surgical antennas and the unavailability of transfusion products could explain our results.

During our study we found an obstetric lethality rate equal to $3.9 \%$, about four (4) times higher than acceptable standards (1\%). This obstetric mortality rate has gradually increased from $3.1 \%$ in 2012 to $4 \%$ in 2013 , then $4.7 \%$ in 2014 and finally $5.2 \%$ in 2015 in the UTH-YO maternity ward.

Our results are lower than those of Soma N [18] which found a lethality rate of $5.79 \%$ in a study conducted from 2003 to 2005 at the Yalgado Ouédraogo University Hospital Centre.

This decrease in the case-fatality rate can be explained by progress and strengthening in the accessibility of Emergency Obstetric Care and the state's policy of subsidies to reduce care costs. Nevertheless, more needs to be done, as this rate is still high in accordance with the accepted threshold of $1 \%$ according to the WHO.

This still high rate could be explained by the socio-cultural gravity marked by a strong attachment to traditional practices with the use of traditional birth attendants who are often poorly qualified. On the other hand, it should be noted that women, especially those living in rural areas, have little decision-making power to attend health facilities. All these factors limit women's access to quality care, thus worsening the prognosis for obstetric complications. To this must be added the inadequacy of the technical platform and the nonfunctionality of some health centres from which they are very often referred very late.
In addition, our results are close to those of Gbangbade $\mathrm{S}$ and al. [6] in a 2006-2015 study conducted in Benin that found an obstetric lethality rate of $3.5 \%$; and higher than those of Mbola Mbassi S and al. [19] in Cameroon in a study from 2004 to 2011 that noted a lethality rate of $2.2 \%$.

In our study, the most lethal causes were: thromboembolic pathologies $(27.27 \%)$, infections $(13 \%)$, abortion complications (7.6\%), bleeding (5.4\%) and hypertensive disorders (4.2\%).

Our results could be explained by the fact that thromboembolic pathology is a formidable complication in her breast which, once installed, reveals a poor prognosis in the majority of cases $(80 \%)$. Also the high cost of treatment is also one of the factors that prevents effective management, hence the high case-fatality rate observed. As for infections, which often occur late, they are dominated by sepsis and septic shock, the prognosis of which is poor and the risk of death is $99 \%$ due to the lack of effective resuscitation methods. Abortions, very often performed in secret and under poor hygienic conditions, expose women to the risk of infection and bleeding; most of the time, patients are admitted in an already critical condition, which could explain this high lethality.

Bleeding and hypertensive disorders accounted for the highest number of cases of direct obstetric complications with respectively (2555 cases) and (2034 cases) but had the lowest case-fatality rates $(5.4 \%)$ and $(4.2 \%)$. This could be explained by improved management with the availability of blood derivatives, the use of antihypertensive and anticonvulsant drugs, and finally surgical management.

Our results are different from those of Soma N [18] which found the most lethal complications to be: puerperal infections $(44.44 \%)$, anemia $(17.95 \%)$, pre ruptures and uterine ruptures $(10.57 \%)$, preeclampsia and eclampsia $(6.02 \%)$.

\subsection{Period of Maternal Deaths}

Women who died in the postpartum period accounted for $43 \%$. Our results are lower than those of Abdourhamane [1] in Bamako, who accounted for $64.6 \%$ of women who died in the postpartum period; and those of Akpadza and al. [2] in Lomé, which found $59.5 \%$. According to WHO, about $45 \%$ of maternal deaths in the postpartum period occur within the first 24 hours, then $2 / 3$ in the first few weeks. A similar finding has been reported by many authors [7, 8, 17, 19]. This finding could be explained by:

1) Inadequate postpartum surveillance

2) Difficulties in managing complications of childbirth in peripheral and urban maternity hospitals.

3) Difficulties in managing intensive care due to the poor condition of evacuated women

4) Non-compliance with asepsis rules.

In our series, more than half of maternal deaths, or $63.7 \%$ of women, died within the first 24 hours of admission.

Some authors have made the same observation:

1) Iloki and al. [10] in Brazzaville, found 57.3\% of the women who died in the first few hours after admission.

2) Abdourhamane [1] in Bamako, found $71.1 \%$. 
3) Lankoandé and al. [11] in Ouagadougou, found 71.5\%.

These figures reflect the extreme seriousness of the condition upon admission. The condition of women who died on admission is the result of three fatal delays for the mother and her newborn child. The time to death is also related to the cause. Indeed, the infection is slower to develop, while severe bleeding is quickly fatal before the patient is even evacuated.

\subsection{Causes of Maternal Deaths}

Direct obstetric causes are the leading cause of maternal mortality in the world. They represent $85.1 \%$ of the causes of death in our series; $69 \%$ in Abdourhamane's series [1].

Among the direct causes, bleeding accounts for $33.5 \%$ and was the leading cause of death in our study, followed by abortion complications $24 \%$ and hypertensive disorders $21.1 \%$, infections $17.2 \%$. According to WHO, between $11 \%$ and $17 \%$ of hemorrhage deaths occur during childbirth and 50 to $71 \%$ during the postpartum period [16]. Abdourhamane [1] in a study conducted at the University Hospital of Bamako in 2008 found in variable proportions $25.3 \%$ of causes by haemorrhages; $17.1 \%$ by hypertensive disorders; $10 \%$ for infections; $7.6 \%$ for abortion complications

Leke [12] at Yaoundé Central Hospital in 2004 found 25\% of the causes of death by hemorrhage; $15 \%$ by infection; $13 \%$ by abortion complications and $12 \%$ by hypertensive disorders. Iloki and al. [10] at Brazzaville University Hospital in 1997 found $40.5 \%$ of the causes of death from hemorrhage; $31.5 \%$ from infections; 23.7 from complications of abortion and $12.6 \%$ from hypertensive disorders.

Better coverage of the availability of blood and these derivatives would significantly reduce deaths from bleeding.

The high prevalence of infection $(17.2 \%)$ could be explained by:

1) Poor hygiene in most parturient women

2) Weak asepsis in delivery rooms

3) Dystocic and/or induced childbirth.

Improving infection control in our clinical practices would significantly reduce the occurrence of infections in patients.

The morality rate related to complications of clandestine abortions (24\%) could be explained by under-use of contraceptive methods, lack of sexual education for adolescent girls and very restrictive legal provisions on the voluntary termination of pregnancies. Our results are essentially identical to those of the 1999 Demographic Health Survey, which estimated that $22.1 \%$ of deaths are related to abortion complications [5] and would therefore reflect an improvement in contraceptive prevalence. Further reduction in deaths should guide policies towards improving health coverage to avoid unwanted pregnancies and complications of clandestine induced abortion.

Hypertensive disorders with $21.1 \%$ were favoured not only by the low socio-economic level of women, which would explain the absence or poor quality of prenatal care, but also by the delay in obstetric evacuation.

Improving the quality of ANCs with early detection of related danger signs would improve the prognosis for pregnancy-related hypertension.
Indirect obstetric causes accounted for $14.9 \%$ in our study. Malaria is the second most frequent indirect cause. This is a reminder of the importance of anti-malarial chemoprophylaxis, the use of treated mosquito nets and proper management of malaria cases during pregnancy in our endemic context.

Pregnancy in sickle cell disease is possible but must be planned because it is at risk. The latter can be a risk factor for severe maternal and fetal complications even when appropriate preventive measures are used. Complications are frequent at the end of pregnancy, and are aggravated by the existence of an associated pathology. The management of these patients must be multidisciplinary.

\subsection{Contributing Factors to Maternal Deaths}

Factors contributing to maternal deaths were mainly delay in evacuation, delay in consultation, delay in care, lack of transfusion products, lack of financial resources. Financial problems were identified in $23.3 \%$ of cases among the associated factors. The results are significantly lower than those of Bohoussou and al. [4] who estimated that in $42 \%$ of cases, the financial responsibility of the woman and her family is involved in the delay in care. This difference could be explained by the implementation of the emergency obstetric care in second and third level hospitals, which have a positive impact on this contributing factor. The lack of transfusion products has been identified in $27.2 \%$ of cases and often makes it impossible to provide adequate treatment for certain diseases, so that health personnel are powerless to assist in the tragedy at hand. Lekë [12] in a study conducted by Yaoundé Central Hospital found $7.69 \%$ of the factors associated with the lack of blood products.

The notion of the three delays was rediscovered for the:

1) First delay, which is the delay in consultation of $30.8 \%$ and could be explained by the persistence of harmful socio-cultural constraints, misperception of risks and lack of awareness of danger signs.

2) second delay which is the delay in evacuation $32.7 \%$ and would result from the geographical inaccessibility of health services, insufficient financial means to pay for transport costs, insufficient adequate means of transport sometimes non-existent.

3 ) third delay which is the delay in treatment $31.4 \%$ and could be explained by the insufficiency of the technical platform, the lack of transfusion products, the insufficiency of competent personnel in emergency obstetric care at all levels of the system

In our series, $60 \%$ of patients received surgical management after more than an hour of waiting. For Bohossou and al. [4], this delay ranged from 5 hours to 10 hours 27 minutes, Soma N [18] in the same department noted that $48.9 \%$ of women who had to undergo surgery had to wait more than one hour.

Indeed, this long wait is due to:

1) the inadequacy and availability of the operating room

2) Insufficient human resources

3) The lack of care materials (cesarean section kits often 
incomplete or out of stock).

\section{Conclusion}

Based on our results, it appears that direct obstetric complications remain the main causes of death among women in labour. The main direct obstetric complications implicated were: haemorrhages, abortion complications, hypertensive disorders, infections, dystocias and thromboembolic pathologies. Overall lethality during the study period was 4 times higher than the desired standards (1\%). This study also allowed us to identify multiple difficulties encountered in the health system of our country. It is therefore imperative for us, health actors and the community to work to strengthen our efforts to eradicate this scourge, which can only be solved through participation and collective effort.

\section{References}

[1] Abdourhamane M. Mortalité maternelle au CHU Gabriel Touré: de l'épidémiologie à l'audit. Thèse de médecine, faculté de médecine, de pharmacie et d'odontostomatologie de Bamako, 2008, n॰110: 130.

[2] Akpadza K, Dapam N, Agbetra N, Bassowa A, Agbekponou K, Hondegla A, Aboubakari A. Evolution de la mortalité maternelle au CHU Tokoin de Lomé de 2005 à 2007 et de 1987 à 2005. Méd d'Afr Noire 2007: 29: 110-125.

[3] Andriamady C. L, Rakotoarimanana M, Ranjalahy R. J. Mortalité maternelle à la maternité de Befelatanana CHU d'antananarivo (1988-1997). In J Gynecol Obstet Biol Reprod. 2000 Mars; 29: 501-508.

[4] Bohoussou M. K, Djanhan Y, Bokassa E., Koné N, Welffens E, Toure K, Thonneau P. La mortalité maternelle à Abidjan 1988 à 1993. Méd d'Afr Noire: 1995; 42: 481-484.

[5] Buor D, Bream k. An analysis of the determinants of maternal mortality in sub Saharan Africa. J Women's health (Larch MT), 2004; 13 (8): 926-38.

[6] Gbangbade S. Mortalité maternelle et néonatale au Bénin, 2006 à 2015. Revue Méd Afr Noire: 4-5; 48.

[7] Grady K, Ameh C, Adegoke A, Kongnyuy E, Dornan J, Falconer T, Islam M, van den Broek N. Improving essential obstetric and newborn care in resource-poor countries. J Obstet Gynaecol. 2011; 31 (1): 18-23)

[8] Homer C, Clements V, McDonnell N, Peek M, Sullivan E. Maternal mortality: what can we learn from stories of postpartum haemorrhage? Women Birth. 2009 Sep; 22 (3): 97 104.
[9] Hamadou S, Khoudayer H, Zina H, Masmoudi A, Bouguerra B, Sfar R. la morbidité maternelle grave. J Gynecol Obstet Biol Reprod 2007; 36: 694-698.

[10] IIoki LH, G'bala Sapoulou MV, Kpekpede F, Ekoundzola JR. Maternal mortality in Brazzaville (1993-1994). J Gynecol Obstet Biol Reprod. 1997; 26 (2): 163-8.

[11] Lankoande J, Toure B, Ouedraogo C, Ouedraogo A, Dao B, Kone B. Mortalité maternelle à la maternité du centre hospitalier dOuagadougou à propos de 123 cas colligés en 1995. Méd d'Afr Noire 1998; 187-190.

[12] Leke R. Postgraduates Research Training in reproductive Health 2004. Santé Yaoundé 2004.

[13] Ministère de la santé Burkina Faso. Comité national de suivi de la mise en œuvre des programmes de stratégies de réduction de la Mortalité maternelle et néonatale. Consulté le 10/04/2016 au site: http://countryoffice.unfpa.org/burkinafaso.

[14] Ministère de la santé Burkina Faso. Direction des Etudes et de la Planification (DEP); consulté le 08/04/2016 au site: http://cns.bf/IMG/pdf/ASS_2002.pdf.

[15] OMS. (2015) Mortalité maternelle dans le monde, consulté le $10 / 04 / 2016$ au site: http://www.who.int/mediacentre/factsheets/fs348/fr/pdf.

[16] OMS. (2005) -Donnons sa chance à chaque mère et à chaque enfant. Rapport sur la santé dans le monde Genève. Consulté le 7 avril 2016 au site: http://www.who.int /whr//fr.

[17] OMS/FNUAP/UNICEF/Banque mondiale. (1999) -Réduire la mortalité maternelle: Déclaration commune des agences de l'ONU. Genève. Site consulté le 08/4/2016. http://www.who.int/reproductivehealth/publications/mortalite maternelle/mortalité.

[18] Soma N D. Evolution du taux de létalité des urgences obstétricales à la maternité du CHU/YO de 2003 à 2005. Thèse de médecine UFR/SDS 2007; n॰ 56-63.

[19] Symplice Mbola Mbassi. Soins obstétricaux d'urgence et mortalité maternelle dans les maternités de troisième niveau du Cameroun: approche évaluative d'une intervention visant à améliorer le transfert obstétrical et la prise en charge des complications maternelles. Th de méd. Université Pierre et Marie Curie - Paris VI, 2014: 31-40.

[20] Takpara I, Adisso S, Alihonou E, Souza J, Dolo A, Donoumassou S. Evolution de la mortalité maternelle au CNHU de Cotonou. Bénin médical 2007: 36.

[21] Zongo A, Dumont A, Fournier P, Traore M, Kouanda S, Sondo B. Effect of maternal death reviews and training on maternal mortality among cesarean delivery: post-hoc analysis of a cluster-randomized controlled trial. Eur J Obstet Gynecol Reprod Biol. 2015 Feb; 185: 174-80. doi: 10.1016/j.ejogrb.2014.12.023. Epub 2015 Jan 3. 